\title{
Real time modified programmable universal machine for assembly (PUMA) 560 with intelligent controller
}

\author{
Yousif I. Al Mashhadany ${ }^{1}$, Wesam M. Jasim² \\ ${ }^{1}$ Department of Electrical Engineering /College of Engineering, University Of Anbar, Iraq \\ ${ }^{2}$ Information Systems Department/ College of Computer Science and Information Technology, university Of Anbar, Iraq
}

\begin{tabular}{|c|c|}
\hline Article Info & ABSTRACT \\
\hline & \multirow{10}{*}{$\begin{array}{l}\text { In this work, the design of an integrated industrial application for use on a } \\
\text { modified PUMA } 560 \text { robot arm was presented. The modified PUMA } 560 \text { robot } \\
\text { has three joints; two of them are free-moving and the third one is at constant } \\
\text { 90-degree angle. It has three links and two extra Griper links. Each joint was } \\
\text { controlled via a DC motor through a PIC microcontroller. The design and } \\
\text { implementation of modified PUMA } 560 \text { with electronic circuits to derive the } \\
\text { motor were used with the robot and the working platform. These electronic } \\
\text { circuits were also used to interface with the computer to control the DC motor } \\
\text { based on the computer orders. The control signals used to control the } \\
\text { application control system and to perform the defined tasks were received from } \\
\text { a remote computer connected via internet. This design has been implemented } \\
\text { in two phases; the first phase was the simulation of the complete control } \\
\text { system, while, the second phase was the practical implementation. } \\
\text { The obtained results were ensured the ability of the proposed system to } \\
\text { perform the tasks of many industrial applications. }\end{array}$} \\
\hline Received Mar 1, 2020 & \\
\hline Revised May 25, 2020 & \\
\hline Accepted Jun 26, 2020 & \\
\hline Keywords: & \\
\hline Industrial applications & \\
\hline Interface computer & \\
\hline Kinematics solution & \\
\hline Modified PUMA 560 & \\
\hline PIC microcontroller & \\
\hline
\end{tabular}

Copyright (C) 2020 Institute of Advanced Engineering and Science. All rights reserved.

\section{Corresponding Author:}

Yousif I. Al Mashhadany,

Department of Electrical Engineering,

College of Engineering, University of Anbar, Iraq

Email: yousif.mohammed@uoanbar.edu.iq

\section{INTRODUCTION}

Control (especially remote) via computer is one of the most and sophisticated techniques in engineering applications. Robotic technology uses the artificial intelligence techniques to in its control system $[1,2]$. A robot is a smart programmable and/or connectable mechanical machine to a computer to perform the tasks. Its smart capability gives it a degree of freedom to function synchronously with advanced technology the facilitating global industrial processes. Robots exist in industry (e.g., welding, assembly, and painting) as well as healthcare (e.g., surgery, drug delivery, and sample transfer). They also can be used in fires fighting, discovered and defused explosives, and explored space [3-7].

The importance of this research is materialized out of three basic pillars. The first pillar is the accurate industrial operational control based on the use of the internet technique. This opened the door to research on the scale that can be invested in a future replacement of the means of communication via the Internet through wired or wireless networks [8-12]. The second pillar is the use of the microcontroller technology and programming it to control several events by installing a simple electronic circuit with non-complex repetitive adjustments $[13,14]$. By changing the code and re-injected it in the microcontroller, especially if we passed the complexities of the operating circuits that are used as a transmission medium between the controlled and the controlling systems [15-18]. As the levels of emerging reference signals such as voltages and currents of values do not fit with the system, running circles or the so-called circuit condition is needed [19-24]. The third pillar is to highlight the importance of research in the possibility of building a robot arm with the possibility of the initial design work and simulate more than one program to make sure the preliminary results, before the 
practical implementation and the matching process results confirm the possibility. Research with any practical application is needed or protected market without relying on foreign expertise [25, 26].

Programmable Universal Machine for Assembly (PUMA) is an industrial robot arm developed by Victor Scheinman at Unimation in 1978. It is available as PUMA 260, PUMA 560, PUMA 761, etc. The one we used was the PUMA 560 robot manipulator. The rest of this paper is organized as follows: Section II describes the custom- modifying the PUMA560 robot manipulator. Section III illustrates the Implementing the modified PUMA 560 robot. Section IV shows the designing and implementing of the interface cart for the computerized control. The simulation and practical results are presented in section V. The conclusions are presented in section VI.

\section{PUMA 560 MODIFICATION}

Simulation is one of the most reliable methods that designers use to rationalize costs-not only financial cost but also time and human effort costs. The system design method relies upon the simulation to achieve the advanced level of quality, since the work in the actual process environment without relying on the principle of increasing the quality of the system performance by trial and error. This may lead to failure in the practical application of designed system. Constructing an environment work to mimic the actual one using reliable software combined by means of the processing equipment for training the simulation and compatible with the equipment that will be used in real practical system. It is worth to mention that, it is wrong to equip the real system with different equipment that used in simulation.

\subsection{Reconstruction Of Special PUMA 560 Robot}

The application does not need the entire PUMA 560 arm. A suitable practical arm will be designed based on solving the arm's equations of motion. The modified PUMA 560 have four joints and four links. The joints are; base joint, shoulder joint, elbow joint, and gripper joint. The roll and pitch joints of PUMA 560 have been left out. The shoulder joint is designed for a 90-degree installation. Moreover, the modifications of the robot is reduced the total costs of the robot.

\subsection{Solution Of The Kinematics Of The Modified PUMA 560}

The modified PUMA 560 is shown in Figure 1. Analytic Solution of inverse kinematic can be obtained using the analytical methods and the use of polynomial Denavit-Hartenberg (DH) coefficients. More details of the forward and inverse kinematics can be found in [7], [24].

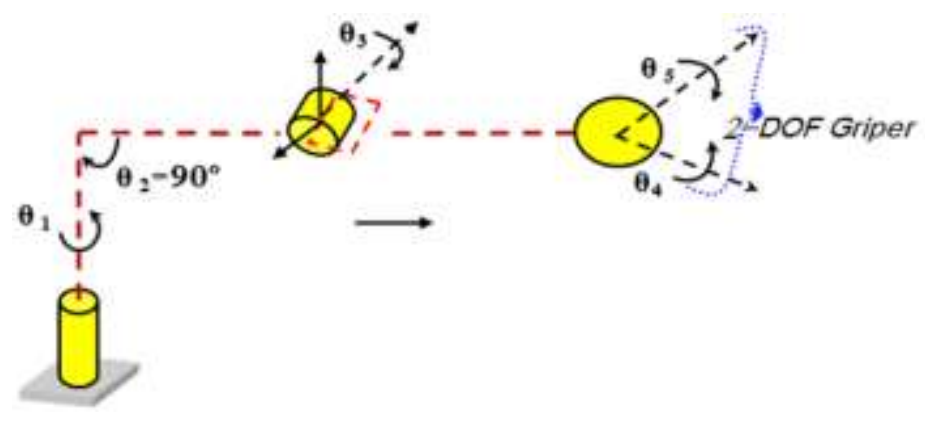

Figure 1. The modified PUMA 560 robot

\section{IMPLEMENTATION OF THE MODIFIED PUMA 560}

The modified PUMA 560 is designed to carry material and transfer it from a location to another. This can be done depends on the algorithm injected on the microprocessor.

\subsection{The Motor Links and Joints}

The modified PUMA 560 has three links. The first link (Link 1) has a length of $28 \mathrm{~cm}$ and a weight of $350 \mathrm{~g}$. It is placed between the base motor and the shoulder joint. The second link (Link 2) has a length of $22.5 \mathrm{~cm}$ and a weight of $500 \mathrm{~g}$. It is placed between the shoulder joint and the elbow joint. The third link (Link 3 ) has a length of $18 \mathrm{~cm}$ and a weight of $300 \mathrm{~g}$. It is placed between the elbow joint and the gripper joint. All the joints that connect the links are controlled by four DC motors. Two identical motors are constructed at the base and at the elbow joints. These motors shown in Figure 2 and some of its specifications are, it is operate at 
voltage of $12 \mathrm{~V}$, relative slow speed about $45 \mathrm{rpm}$, high torque of about $3.5 \mathrm{Nm}$, and 2-direction revolution (clockwise and counterclockwise).
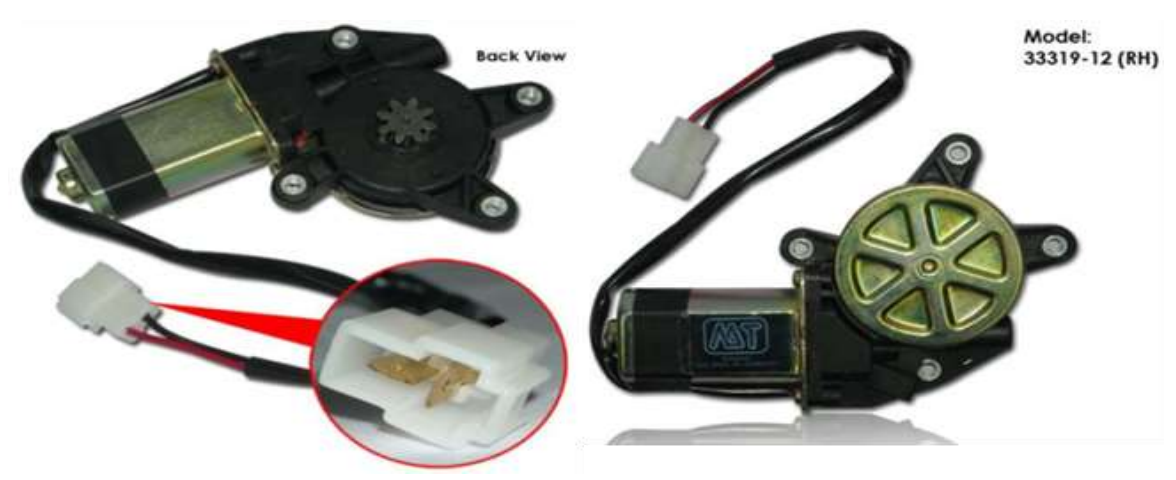

Figure 2. The DC motor used at the base and the elbow joints

The second two identical motors are constructed in the gripper. These motors shown in Figure 3 and some of its specifications are, it is operate at voltage of $12 \mathrm{~V}$, supply current of $0.07 \mathrm{~A}$, speed of $300 \mathrm{rpm}$, torque of $0.0564 \mathrm{Nm}$, and 2-directional revolution (clockwise and counterclockwise).

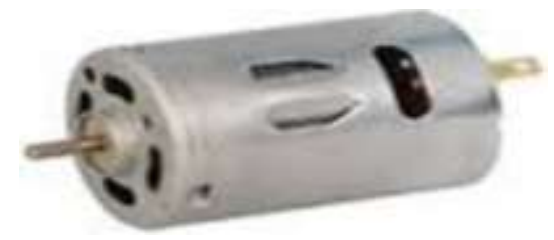

Figure 3. The DC motor used in the gripper.

The modified PUMA 560 has three joints; two free-moving and one fixed at 90-degree angle. These three joints connect the three links. Each moving joint is controlled by a DC motor. The gripper is located at the end of the arm. The whole arm manipulator is fixed to the center of the ground platform as shown in Figure 4 with initial form of design and final form of modified PUMA 560. The ground platform is a square aluminum base of $1 \mathrm{~m}$ dimension and $20 \mathrm{~cm}$ height.

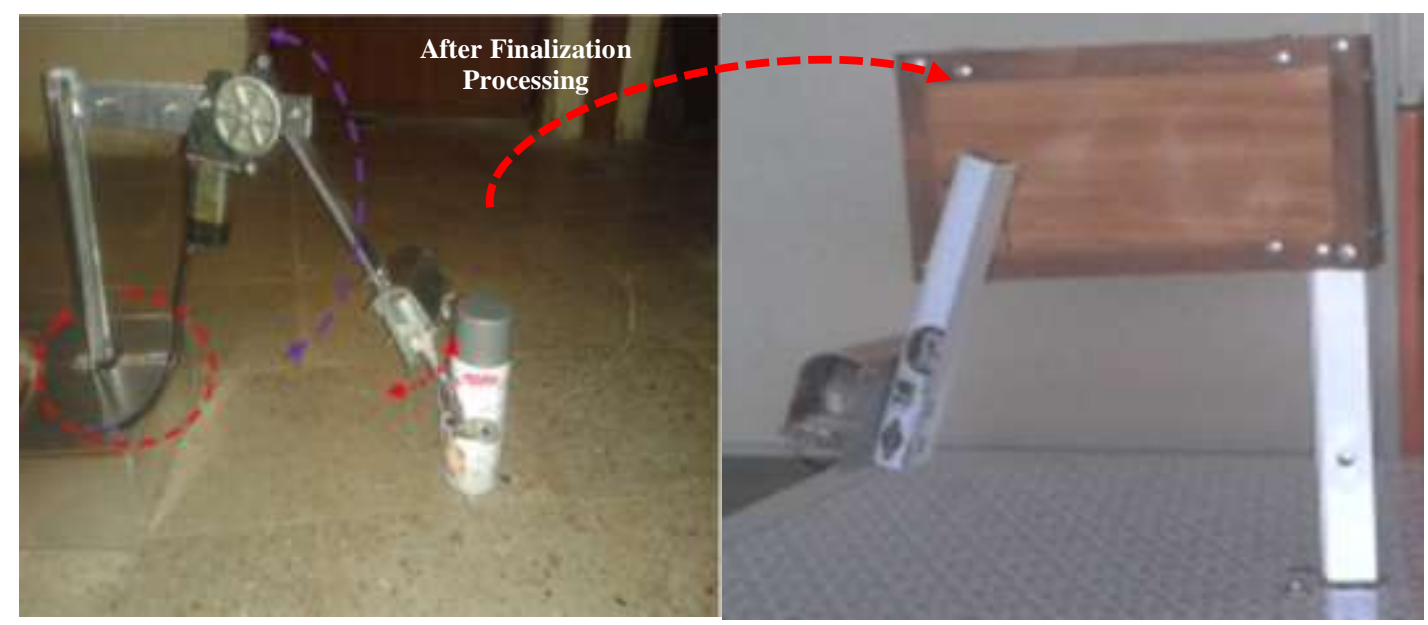

(a)

(b)

Figure 4. (a) Initial form of proposed design. (b) The final form of the modified PUMA 560 


\section{THE INTERFACE CART}

The computerized control system is divided according to the direction of the data to two sections; the offline control (negative control) and the online control (active control). They can be done in several ways with checking one condition. This condition is to check the possibility of the output (voltages) that can deals with the main motherboard four voltages $(-5,+5,-12,+12)$ volts, as these voltages are most often required in the control circuits according to the application and its complexity.

In Figure 5, design the system is controlled by computer via an interface with the ability to give $5 \mathrm{~V}$ output voltage, which entered legged to control the exact required functions. This $5 \mathrm{~V}$ output voltage is the required voltage to signify the start of the required event in the application process. Moreover, the code can be use a Vac (DECODER) through decoding symbols emerging from the computer, then, it is used as input to the microcontroller. A parallel entrances cable (parallel port) is used to control the system through its own program, see Figure 5.

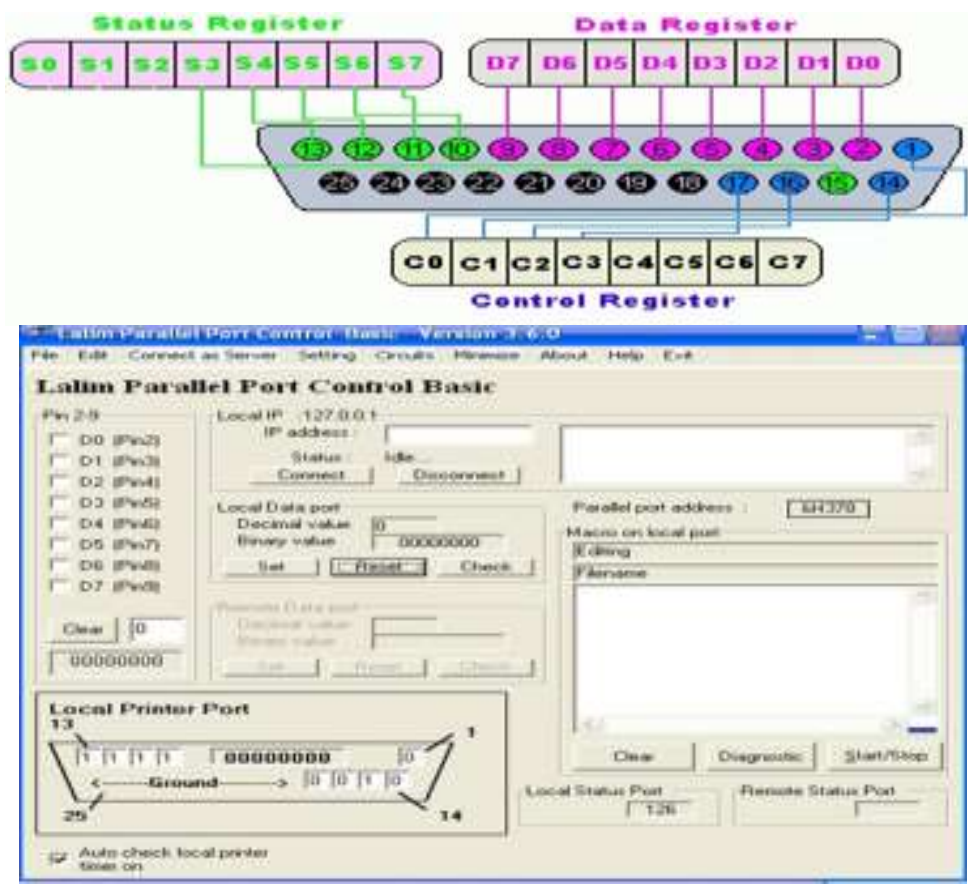

Figure 5. Parallel connection

The control action can be effected by two main methods:

1. Control through the Internet: two computers are used; one to capture the status of the PUMA 560 through a camera (video signal). While, the second computer is replaced in a controller room at any distance (in another country, even). This second computer prepares the order through the TEAM Viewer program used for interconnecting the two computers to the internet network, see Figure 6. This program is used with Dual-Tone Multi-Frequency (DTMF) signaling technique to generate the code between the two computers, and by definition for the ID of two computers to apply full compactable system of interface controller as one unit between control room and robot.

2. Direct control: in which, the control instruction is calculated and then transferred to the robot through a cable of any length, i.e., a single computer applies the control.

In the above two control methods, the instruction transfers to the robot through a microcontroller. Then, the microcontroller translates the control order to the four joints on the robot, with a specific angle to the desired trajectory/posture. A microcontroller PIC16F887 is used to apply the control action. The PUMA contains four joints: base joint, elbow joint, and two joints for the gripper. The control of each motor is applied through two directions relay. It utilizes the microcontroller PWM.

Figure 7 illustrates the use of the Proteus program in designing the drive circuit and injecting the program into the microcontroller PIC16F887 memory through Easy PIC6 card shown in Figure 8 with Micro $\mathrm{C}$ language. Figure 9 shows the electrical circuit of the three motors and the controller with an external oscillator. 


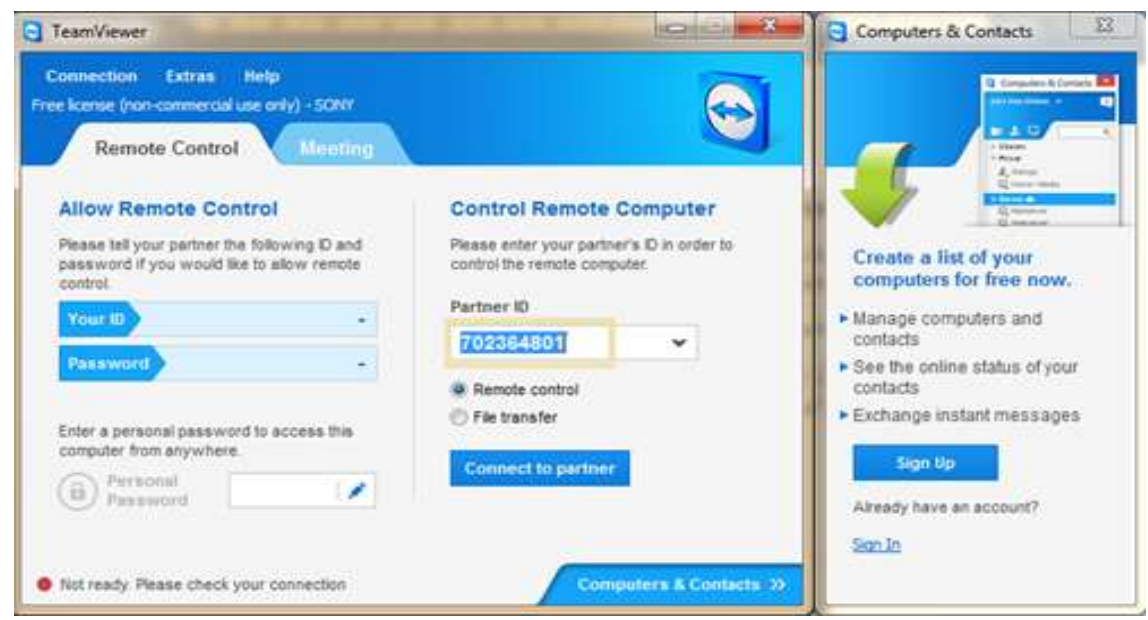

Figure 6. The TEAM viewer software

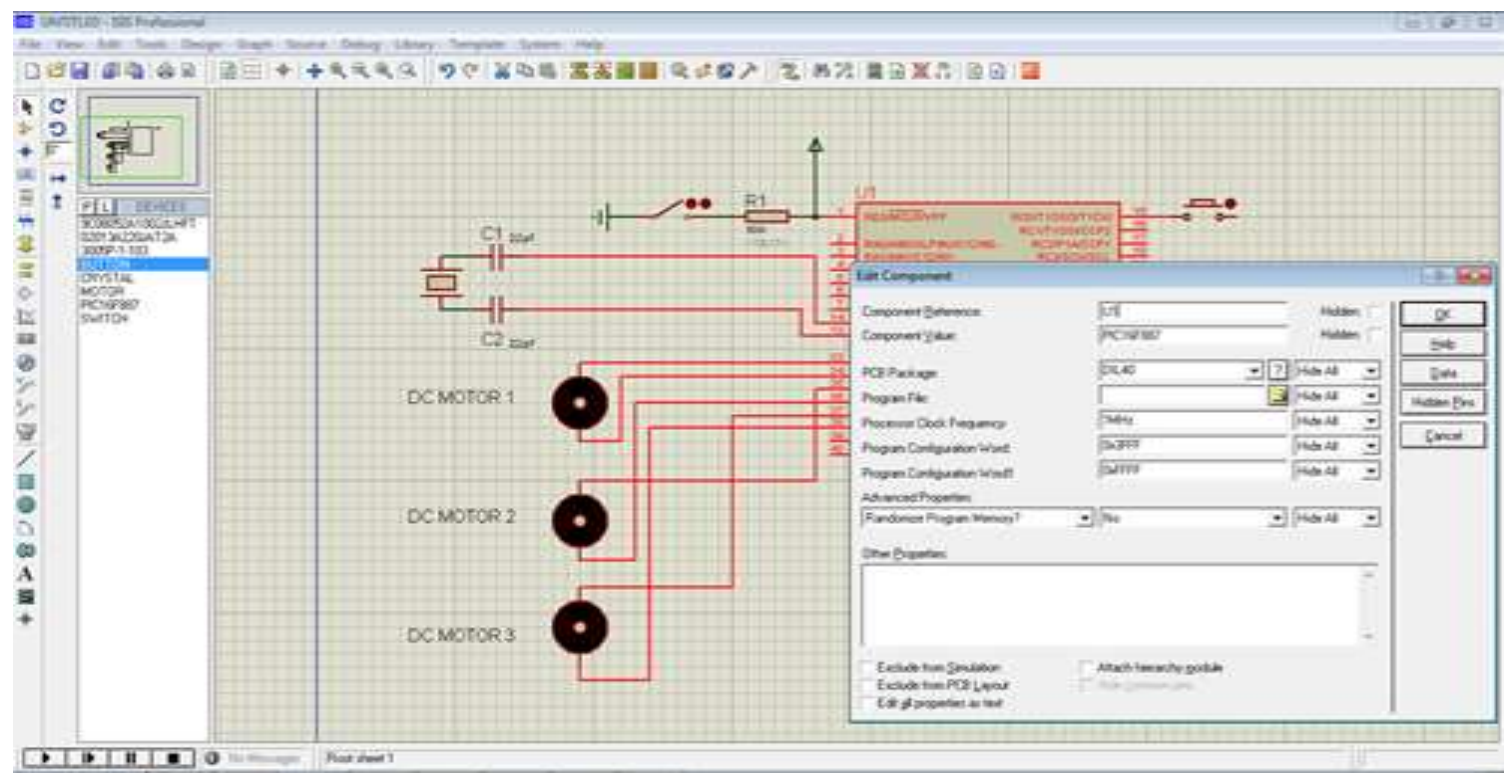

Figure 7. Designing the drive circuit for the robot joints via proteus program

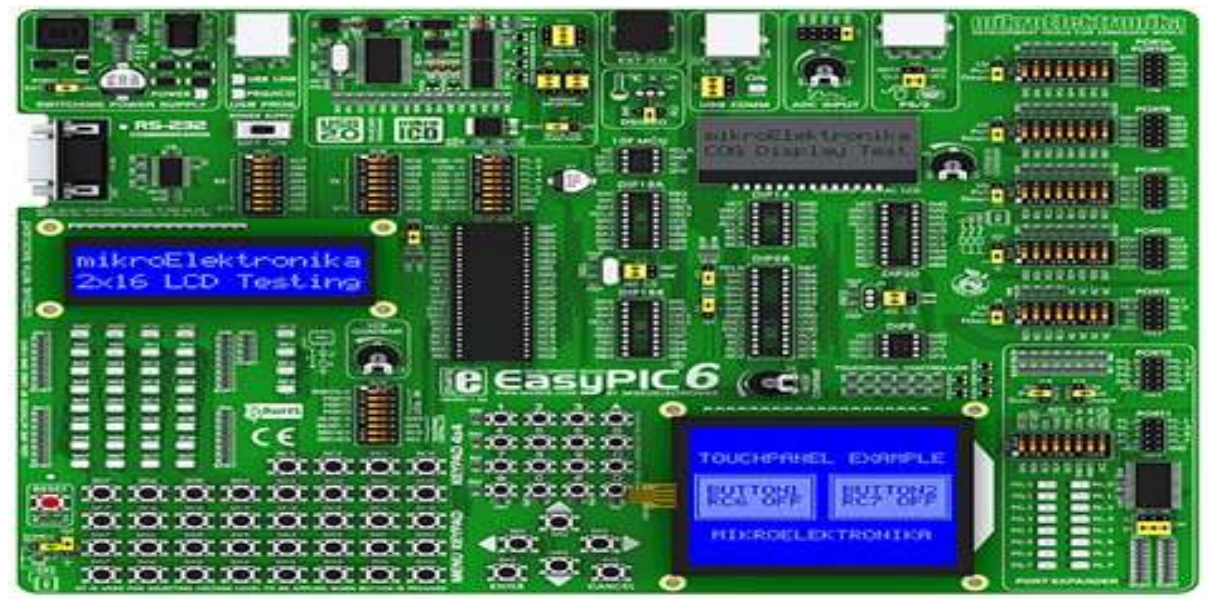

Figure 8. Easy PIC6 simulator for the microcontroller

Indonesian J Elec Eng \& Comp Sci, Vol. 20, No. 3, December 2020 : 1194 - 1202 


\section{SIMULATION AND PRACTICAL RESULTS}

The accuracy of the practical applications results depends on several issues, including the extent of matching accounts for physical elements in mathematical models for design and the accuracy of the obtained simulation results.

\subsection{Simulation Results for Movements of the Motor Joints}

It is well known that the microcontroller outside current is little-insufficient to run the motors directly. Thus the ICs are used to enlarge the current arbitrator, and the relays are applied to make the motors run in both possible directions. The ULN2003a integrated circuit contains transistors linked to enlarge the outside current which is called Darlington current linkage. Figure 9 shows the using of ULN2003a IC, the relay, and the Darlington connection. The program used for electrical simulation is the Proteus program. All these components and program are available in the microcontroller family. Figure 9 shows the circuit connection of motors.

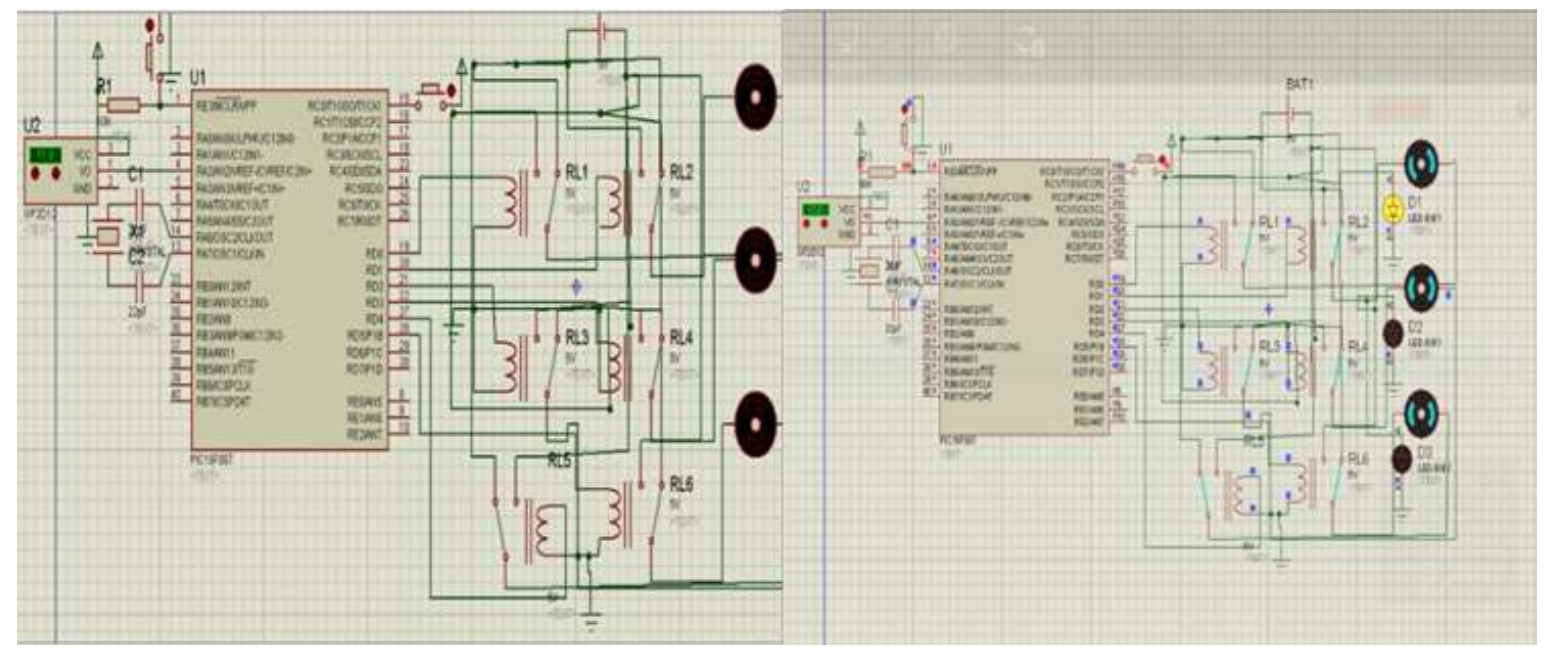

Figure 9. Simulating the motor circuit

Upon running the program, the first LED representing the base motor lights up, then the second LED representing the second motor lights up, next the third LED representing the gripper motor lights up. Figure 9 shows the three motor's diagram.

\subsection{Simulation of the Whole Trajectory with Many Jobs}

The robot circuit is as shown in the Figure 9. Three motors are connected to the PIC microcontroller $16 f 887$ through a $12 \mathrm{~V}$ DC relay. Each DC motor connected with two relays to reverse the motor's direction. The motor position is controlled based on a PIC microcontroller via PWM. The PUMA 560 works in two control ways:

1. Controlled by the microcontroller: in which the motor receives the commands from the microcontroller. Then it demonstrates a particular process as pre-determined by the PIC. Several operations that the PUMA is able to do can be stored via a program. Other operations can be added by injected it inside the microcontroller because the microcontroller can be programmed many times.

2. Controlled by computer: in which the motor receives the commands from the computer through a PIC microcontroller. The computer sends the commands via parallel ports to the microcontroller. Then the microcontroller transfers the commands to the PUMA.

\subsection{Practical Implementation of the Whole Design}

The suggested movability is a circular motion with 360 degrees in the base joint, bidirectional (clockwise and counterclockwise). This enables the robot to reach the largest possible area. Consequently this enables the robot to transport the products to any place within the work environment. The second joint is fixed at 90 degrees to extend the arm movement from the robot's center. The third joint, which holds the gripper, is to move 180 degrees up and down so the robot can perform the lifting up and putting down tasks freely. The three joints move flexibly can be seen in Figure 10. 


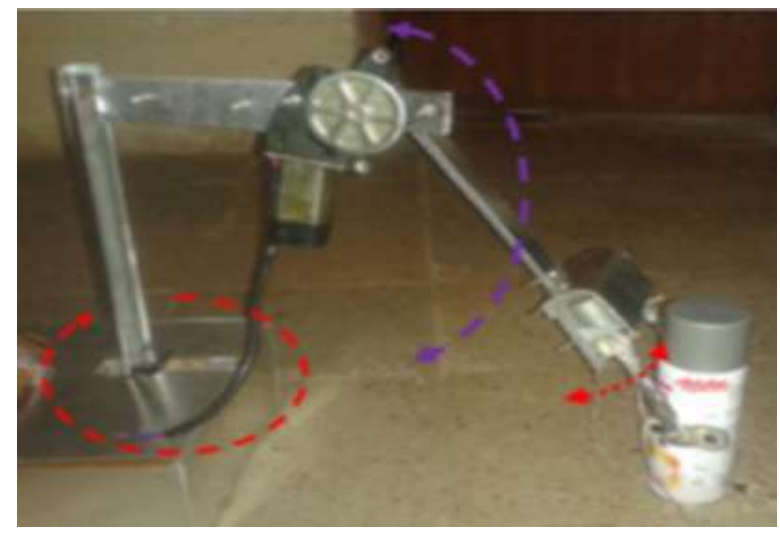

Figure 10. Movement directions and limits of the joints

\subsection{Industrial Applications}

Two tests were conducted to verify the robot control system. The first test is the product transportation test; in which the robot transfers a product from a certain place to another place on the production/ine see Figure 11. This is one of the robot's most important applications.

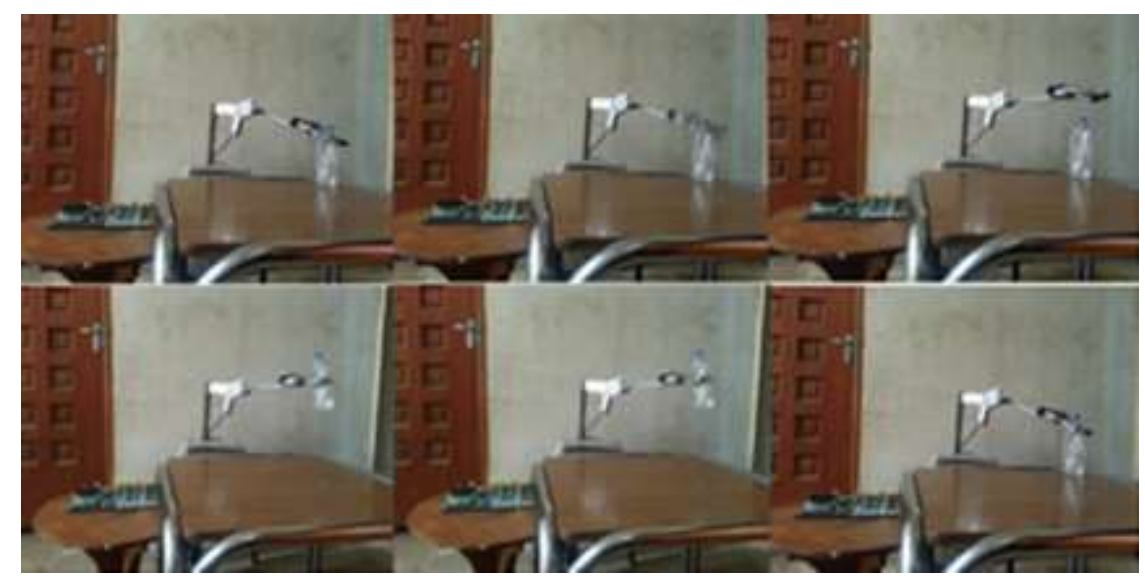

Figure 11. Examples of possible industrial applications enabled by the modified PUMA 560

The second test is one of the most popular industrial applications called the product assembly test; in which the robot assembles a product on the production line before transferring the finished product to packaging, shows Figure 11.

\section{CONCLUSIONS}

There are many control systems in the industrial fields; the most important of these systems are able to execute remote control orders with high accuracy. The proposed system was designed and applied with very high accuracy using the intelligent control system (micro controller) and the use of remote control based control signals using Internet signal technology. The dynamics of the proposed model have been developed, as well as the reverse kinematic solution, which gives a work area with the same dimensions for the original arm in addition to that the path of this arm is very accurate when comparing the theoretical and practical results of the path and for several tasks that it performs.

The system is designed to deal with the signal calculated by the computer's input card and use the Matlab Var.2019a software, and then process the signal calculated in the appropriate sequences according to the desired position, by calculating the required angles for the joints to carry out a specific function. Accurate results were obtained when applying this system, which confirms the possibility of considering this model as an industrial model to enable it to implement the most difficult industrial applications. 


\section{REFERENCES}

[1] S. Alavandar, M. J. Nigam, "Inverse Kinematics Solution of 3DOF Planar Robot using ANFIS", Int. J. of Computers, Communications \& Control,. Vol. III, Suppl. issue: Proceedings of ICCCC 2008, pp. 150-155, 2008.

[2] A. Izadbakhsh, "Closed-Form Dynamic Model of PUMA 560 Robot Arm”, IEEE Proceedings of the 4th International Conference on Autonomous Robots and Agents, Feb 10-12, pp. 675-680, 2009.

[3] Chen X., Xiong C., Xiong Y., "Kinematics Modeling and Simulation of a Passive Four Bar Linkage", IEEE International Conference on Mechatronics and Automation, Changchun, China, pp. 4139-4144, 2009.

[4] Y. I. Al-Mashhadany, "ANFIS-Inverse-Controlled PUMA 560 Workspace Robot with Spherical Wrist", Elsevier Procedia Engineering journal, pp. 700-709, 2012

[5] A. Bendimrad, A. El Amrani, B. El Amrani, "Design and implementation of line follower and obstacle detection robot", International Journal of Power Electronics and Drive System (IJPEDS), Vol.11, No. 1, pp.160-168, 2020.

[6] Q. V. Ngo1, C. Yi,and T. T. Nguyen, "The fuzzy-PID based-pitch angle controller for small-scale wind turbine", International Journal of Power Electronics and Drive System (IJPEDS), Vol. 11, No. 1, pp. 135-142, 2020.

[7] M. Aghajarian, K. Kiani, "Inverse Kinematics Solution of PUMA 560 Robot Arm Using ANFIS", IEEE The 8th International Conference on Ubiquitous Robots and Ambient Intelligence, pp. 574-578, 2011.

[8] A. Izadbakhsh, P. Kheirkhahan, "Voltage-based Control of Robot Manipulators Revisited", International Journal of Control, Automation and Systems, Vol.16. No.4, pp. 1887-1894, 2018.

[9] J. L Patton, G. Dawe, C. Scharver, R. Kenyon, "Robotics and Virtual Reality: The Development of a Life-Sized 3-D System for the Rehabilitation of Motor Function", NIDRR RERC. 0330411Z, NIH 1 R24 HD39627-0, NIH 1 R01NS35673-01, 2012.

[10] H. Reham, A. Mohammed, E.Basem, B. Elnaghi, A. Fahmy, C. Bendary, "Trajectory Tracking Control and Robustness Analysis of a Robotic Manipulator Using Advanced Control Techniques", International Journal Engineering and Manufacturing, Vol. 6, pp. 42-54, 2018

[11] Y. I. Al-Mashhadany, "Inverse Kinematics Problem (IKP) of 6-DOF Manipulator By Locally Recurrent Neural Networks (LRNNs)", International Conference on Management and Service Science (MASS 2010), Aug. 24-26, 2010.

[12] Y. W. Kean, A. Ramasamy, S. Sukumar and M. Marsadek, "Adaptive Controllers for Enhancement of Stand-Alone Hybrid System Performance", International Journal of Power Electronics and Drive System (IJPEDS), Vol. 9, No. 3, pp. 979-986, 2018.

[13] T. Singaraju, T. Metin, S. Bogosyan, "Hardware-in-the-loop simulation of PUMA 560 via internet", 1-4244-01364/06/\$20.00'IEEE, pp. 5426-5432. 2006

[14] S. A Mazhari, S. Kumar, "Heuristic Search Algorithms for Tuning PUMA 560 Fuzzy PID Controller", International Journal of Electrical and Computer Engineering, Vol, 3:4, pp. 286-277, 2008.

[15] Y. I. Al Mashhadany,"SCARA Robot: Modeled, Simulated, and Virtual-Reality Verified", International Conference on Intelligent Robotics Automation and Manufacturing, Malaysia, Nov. 2012

[16] A. Tuan, and H. Kang, "An Adaptive Neural Non-Singular Fast-Terminal Sliding-Mode Control for Industrial Robotic Manipulators". Applied Sciences journal, 8, pp. 2-17, 2018

[17] S. C. Hsiung, "The Use of PIC Microcontrollers in Multi- ple DC Motors Control Applications," Journal of Industrial Technology, Vol. 23, No. 3, pp. 2-13, 2007.

[18] N. H. Lin and C. S. George, " Measurement of the Robot Motor Capability of a Robot Motor System: A Fitts's-LawInspired Approach, Sensors, 13, pp. 8412-8430, 2013.

[19] H. A. Kadhim1, N. S. Ali, D. M. Abdulsahib, "Management and archiving system for metal detection robot using wireless-based technology and online database registry", International Journal of Power Electronics and Drive System (IJPEDS) Vol. 10, No. 1, pp. 219-229, 2019.

[20] Y. I. Al-Mashhadany, "Modeling and Simulation of Adaptive Neuro-Fuzzy Controller for Chopper-Fed DC Motor Drive", IEEE Applied Power Electronics Colloquium, Malaysia, 18 - 19 April, pp. 110-115, 2011

[21] C. Lo, P. Franco, J. Herna, N. Barraga, Y. Alanis, "Inverse kinematics of mobile manipulators based on differential evolution", International Journal of Advanced Robotic Systems, , pp. 1-22, 2018.

[22] Benitez, I. Huitzil, A. Casiano, " PUMA 560: Robot Prototype with Graphic Simulation Environment", Advances in Mechanical Engineering, ISSN: 2160-0619, Vol. 2, No. 1, 2012.

[23] H. Benzater, S. Chouraqui, "PUMA 560 Trajectory Control Using NSGA-II Technique with Real Valued Operators", International Journal of Soft Computing, Mathematics and Control (IJSCMC). Vol. 3, No.3, pp. 13-32, 2014.

[24] Y. I. Al-Mashhadany, "ANFIS-Inverse-Controlled PUMA 560 Workspace Robot with Spherical Wrist", Elsevier Procedia Engineering journal, Vol. 41, pp. 700-709, 2012.

[25] A. Hamed and A. Hazzab, "Modeling and Real-Time Simulation of Induction Motor Using RT-LAB", International Journal of Power Electronics and Drive System (IJPEDS). Vol. 9, No. 4, pp. 1476-1485, 2018.

[26] W. M. Jasim and E. T. Yassen, "High Order Robotics Arm Modelling Based on ANFIS Technique", Journal of Engineering and Applied Sciences, Vol.12: pp. 8689-8694. 2017. 


\section{BIOGRAPHIES OF AUTHORS}

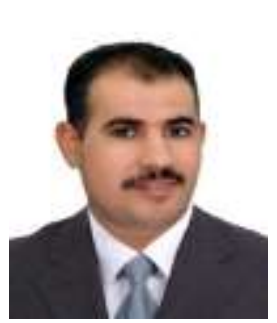

Assist. Prof. Dr. Yousif Ismail Mohammed Al-Mashhadany is a lecturer in Electrical Engineering Department - College of Engineering (Control Engineering). Senior member IEEE, He received the B.Sc. (1995), M.Sc. (1999), and Ph.D (2010) in Department of Electrical and Electronic Engineering from the Rashid School of Engineering and Science / University of Technology in Baghdad/Iraq. He complete postdoctoral fellow research in electrical engineering - control department at the University of Malaya in Malaysia (UMPEDAC) in 2012. He works since 2004, a lecturer in the Department of Electrical Engineering / Engineering College / University of Anbar. He has many publishing that included three books, two chapters, thirty seven Journals paper most of them (Clarivate, Scopus and international journal), and thirty two conferences paper.

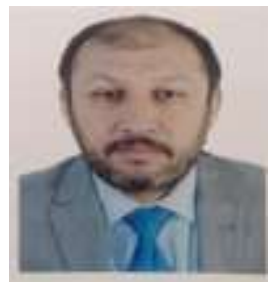

Wesam Jasim received the B.Sc. and M.Sc. degrees in control automation engineering from University of Technology, Baghdad, Iraq, and Ph.D. degree in computing and Electronics from University of Essex, Essex, UK. Currently, he is an Assistant Professor with the College of Computer Science and Information Technology, University of Anbar. His current research interests include robotics, multiagent systems, cooperative control, Robust control, linear and nonlinear control, Deep learning. He has published research papers at national and international journals, conference proceedings as well as chapter of book. 